Research Article

\title{
Safety Analysis of Deep Foundation Excavation in Water-Rich Soft Soils Based on BIM
}

\author{
Huier Xu (iD) ${ }^{1}$ and Shoude $\mathrm{Li}\left(\mathbb{D}^{2}\right.$ \\ ${ }^{1}$ Wentian College, Hohai University, Maanshan 243031, China \\ ${ }^{2}$ College of Civil Engineering, Hohai University, Nanjing 210098, China \\ Correspondence should be addressed to Shoude Li; lishoude@hhu.edu.cn
}

Received 22 May 2020; Accepted 25 August 2020; Published 6 October 2020

Academic Editor: M. I. Herreros

Copyright (c) 2020 Huier Xu and Shoude Li. This is an open access article distributed under the Creative Commons Attribution License, which permits unrestricted use, distribution, and reproduction in any medium, provided the original work is properly cited.

\begin{abstract}
Recent years have seen a great concern on the construction safety of the deep foundation pit with complicated geological conditions due to an increasing number of accidents. However, there are not, currently, sufficient research studies on the safety analysis of the deep foundation pit in water-rich soft soils. As a result, dynamic predictions of the safety risk during the whole construction process are inadequate due to the lack of research studies. Therefore, this paper presents an approach for the construction safety of the deep foundation pit in water-rich soft soils, which combines the building information modeling (BIM), the finite element analysis (FEA), and the finite difference method (FDM). By using BIM technology, the author attempts to establish a 3D information model and a bracing structure model. Based on the application programming interface and the C\# language, the data conversion from BIM-ANSYS-FLAC3D is realized. The author then attempts to analyze the ground surface settlement and horizontal displacement during the excavation of the deep foundation pit through FLAC3D, and the purpose of which is to identify potential safety hazards so that reasonable control measures can be taken. The approach presented in this article has been validated in the Project of Qinhuai River Ship Lock. Since the excavation and the after-construction stages of this project have been completed smoothly, this approach has been proved valid and applicable.
\end{abstract}

\section{Introduction}

The geological environment is extremely fragile in the rivers and coastal areas, the technical challenges and potential safety risks are increasing when the deep excavation passes through the soft layer with the high water content and higher permeability, and accidents happened much more frequently. Therefore, great attention has been paid to scholars all over the world for ensuring the safety in construction [1-3]. Despite constant determination from academic researchers and professionals and imposed control measures, injuries in construction have not significantly dropped [4-6].

Detecting safety hazards and suggesting preventive measures are the fundamental steps for managing safety $[7,8]$. However, in water-rich soft soil areas, due to unpredictable geological and hydrological conditions, it will not be easy to precisely identify the potential safety hazards (such as deformation of supporting structures and ground settlement), as well as take reasonable control measures, and it would require dynamic integration of multisource information which may include monitoring measurements and calculated predictions (from the design data and the continuous monitoring data). Advancing information technology presents an unprecedented opportunity to help improve construction safety [9].

With the high development of computer technology, building information modeling (BIM) has obvious advantages: visual simulation of the construction process and clash detection to optimize the design and construction plan; integration of data for analysis to help improve the decisionmaking process and construction performance [10-12]. BIM's core structural model contains complete information on the physical and functional characteristics of buildings that allow users to extract and use through extended development, which is needed for the deep foundation 
construction safety analysis. But the design data cannot be extracted for the safety analysis during the construction stage because the interoperability issues persist between various software applications (design using CAD or Revit software and safety analysis using ANSYS, Abaqus, or FLAC3D software) [13-16]. Based on this result, geotechnical engineers tried to reestablish the safety analysis model through incomplete sets of input data and to simulate and predict the construction processes [17]. Evaluating the actual construction process by utilizing updated measurement data obtained on site effectively has led to the birth and growth of the observational method [18-20]. The richness in the measurement data and controlling construction in a timely enough fashion by using observed movements are all supporting factors for the successful undertaking of the observational method $[17,20]$.

Although many attempts have been made to implement safety risk analysis using finite element analysis or in the framework of the observational method, in most cases, the solutions have been limited to perform simulation analysis using only measured data instead of using multisource data (such as design data and support structure data). It is difficult to meet the needs of dynamic analysis of underground engineering. BIM technology can achieve these, but it is rarely applied in the geotechnical engineering field, mainly because of lack of interoperability between the software applications and the resulting lack of completed information creating difficulties for engineers to perform a refined analysis and take the effective safety measures for preventing accidents.

This paper proposed an approach for the construction safety of the deep foundation pit in water-rich soft soils. By implementation of the BIM-ANSYS-FLAC3D data conversion, the data of different stages are integrated to analyze the ground surface settlement and horizontal displacement to identify hidden safety hazards in advance which, furthermore, make reasonable control measures timely. The paper is structured as follows: in the next section, we present a review of the literature on the deep foundation construction safety. In Section 3, we present an approach for the construction safety of the deep foundation pit in water-rich soft soils. Sections 4 and 5 present a case study that was performed to validate the proposed method for the construction safety of the deep foundation, and conclusions are drawn in the last section.

\section{Literature Reviews}

Geological conditions of engineering in southern China usually perform more complicated characteristics than others, which have unstable surrounding rock, soft soils, high groundwater level, etc. Accidents happened much more frequently in recent years, which are usually caused by soil displacement and ground settlement on the condition of deep foundation excavation. Therefore, there have been considerable research studies that attempt to analyze and control the construction risk (such as the ground surface settlement and the braced structures' deformation) due to deep foundation excavation, to improve construction safety and efficiency [21-23].

2.1. Observational Method. In recent years, general-purpose numerical analysis techniques, such as finite element methods, have become important tools to predict and assess the safe construction of geotechnical engineering projects. But challenges in using these methods were experienced by geotechnical engineers who tried to simulate the construction process through incomplete data. So the engineers turned their attention to the construction site to obtain enough information for performing reliable predictive analyses. The observational method can provide a solution if one wants to predict and subsequently evaluate the overall performance of a design to assure safe construction. The observational method is a framework wherein construction and design procedures and details of a geotechnical engineering project are adjusted based on observations and measurements made as construction proceeds [20].

any scholars believe that the observational method not only helps provide the assurance of safe construction but also offers many possibilities of spectacular savings of time or money, which were therefore developed and popularized in the geotechnical engineering field [24-26]. Ikuta et al. indicated that monitoring data of the soil and structure behavior during excavation are rarely used to improve predictions and modify the design of subsequent stages of construction due to the variable and complicated retaining wall structure conditions. The observational construction method is proposed whereby the excavation sequence is modified and optimized during construction by using the measured data [27]. Finno and Calvello present a numerical procedure for supported excavation in clays to effectively and efficiently update design predictions of lateral deformations during construction [28]. Calvello presents an approach to update the model predictions of a geotechnical boundary value problem by combining the observational method and inverse analysis techniques, in which two case studies are used to prove the applicability of the proposed approach [29]. To promote the application of the observational method in excavation design, the framework with four design approaches is established and four Crossrail station excavation cases are analyzed; research results show that savings can be achieved on embedded retaining wall design for deep excavation in London Clay without compromising safety [30]. As is pointed out by Peck, "It has been shown that the observational method has its limitations and drawbacks....... Often the procedure is adopted to provide assurance that enough time has passed to achieve some desirable end......" [20]. Although the observational method is very helpful, it is quite difficult to use observed movements for judging quantitatively how well it works and enhancing the safety of construction in a timely enough fashion [28]. A model created by a computer, involving material properties such as geological structures, would best be configured as a better representation of reality, and thus, richness in the measurement data is also beneficial in performing reliable 
predictive analyses. Therefore, the great potential of observation methods can be better exploited by combining the application of modernized measuring instruments, advancing technologies, and efficient data conversion methods [17].

2.2. Numerical Simulation and On-Site Monitoring. The numerical analysis method is an important way to predict and analyze the ground settlement of the deep foundation, and the finite element analysis (FEA) is most typical. Zhang et al. developed a simple polynomial regression (PR) model for estimating the maximum wall deflection for braced excavations in clays, in which the results of case studies show that the reliability of the proposed PR model is given for a variety of wall and soil conditions [31]. In order to effectively predict the potential damage to adjacent buildings caused by excavation, Wang et al. present an approach for the probabilistic inverse analysis of braced excavations based on the maximum likelihood formulation [32]. A multivariate adaptive regression splines (MARS) model and the second MARS model were developed for inverse parameter identification of the soil relative stiffness ratio and inverse parameter estimation of the wall system stiffness, to control the ground movement of a deep excavation during construction for ensuring the construction safety of the deep excavation [33]. Kung et al. have proposed a simplified semiempirical model, and the study shows that the developed model can accurately predict maximum wall deflection and ground surface settlement caused by braced excavations in soft to medium clays [34]. Hong et al. investigated and compared excavation-induced ground deformations in "greenfield" sites and congested sites. Field measurements show that the influence zone of ground settlement at the "greenfield" site is larger than those at the congested sites [35]. Fuentes et al. discuss the implications of the observational method (OM) applied to the foundation pit excavation using the three-dimensional numerical analysis [36]. Houhou et al. analyzed the interaction between the deep excavation under construction and adjacent buildings and compared the set of measurements and the $3 \mathrm{D}$ numerical analysis using a finite difference code. The results show that there was good accordance between the numerical results and monitoring data [37]. The groundwater has a great influence on the stability of the excavation slope when the deep foundation excavation passes through the soft layer with high water content and high permeability. Given the adverse effects, the studies of the ground settlement caused by the deep excavation under groundwater seepage have gradually gone deepened. Benmebarek et al. analyzed the effect of lateral earth pressures acting on deep sheeted excavations in cohesionless soil, in which the numerical results show that a significant increase in the effective active earth pressures is due to a hydraulic head loss [38]. Lim and Ou examine the stress state of soils during deep excavation [39]. A top base method has been used on very soft ground to reduce the consolidation settlement and increase the bearing capacity of a foundation. Arai et al. have conducted experiments in which a $1 / 5$ size model of the top base foundation has been performed and then the coupled stress-flow finite element analysis has been completed. The results show that the top base foundation creates a more uniform distribution of vertical stress so that the bearing capacity can be increased [40].

The data of numerical simulation analysis are mainly derived from the design information or completed project, and these do not fulfill the dynamic and real-time requirements of ground surface settlement prediction during excavation. It is difficult to make optimal decisions since insufficient project data are shared between project team members during the construction phases [41]. If the real-time monitoring data cannot be integrated into the numerical simulation model for the dynamic analysis, these analytical methods must be subject to some restrictions because of the complex effects of soft soil characteristics, groundwater seepage, etc. [42]. To improve the accuracy of ground surface settlement prediction, many scholars experimented with the ways of numerical simulations combined with in situ monitoring to predict and control the settlement and have made significant progress. Tunneling projects receive more attention than the foundation engineering, but the deep excavation is a necessary step in tunneling projects, and thus the analysis methods using the numerical simulations combined with the field monitoring data are consistent for both [43-48].

Ding and Zhou developed a web-based information system for managing, visualizing, and analyzing shield tunnel construction data and applied it to the Shanghai Yangtze River Tunnel project [49]. The research team in Ruhr-University Bochum focused on the mechanical relationship between the tunneling parameters and ground settlement by integrating most of the data induced by shield tunneling [50]. To achieve timely settlement control during shield tunneling construction, Xie et al. designed and developed a real-time mobile interaction and coordinated management platform using the instant messaging (IM) tool and verified in the project of Nanning metro line 1 crossing beneath Nanning railway station [51].

2.3. Combining the BIM and the FEM. BIM is a digital representation of the physical characteristics of a facility providing accurate data throughout the life cycle of projects, which provides a new approach for data integration and construction safety management of projects. To apply the information in the BIM model for the finite element analysis, some significant research studies have been carried out attempting to improve interoperability between various software applications $[15,52,53]$. Some scholars have attempted to study the transformation mechanism between an IFC-based BIM and commercial software tools (such as an XML-based finite element model (FEM)) $[52,54,55]$. Chen et al. developed an IFCbased web server that can be used to generate structural models from the IFC-based architectural models [56]. Based on a data conversion mechanism between an IFC-based BIM and an XML-based FEM, Deng et al. developed an algorithm that the IFC-based architectural model can be automatically converted into the structural models $[57,58]$. To address the interoperability issues in the structural engineering domain and 
enhance interoperability, $\mathrm{Hu}$ et al. propose a novel approach that combines an industry foundation class- (IFC-) based unified information model with some algorithms [15]. Chen proposed a programming interface between BIM and FE software ANSYS and implement the automatic conversion from the BIM model to the finite element (FE) model [59]. Due to the lack of reliable procedures for structural simulation, it is difficult for the numerical characterization of historic buildings with irregular geometry, alterations, and damages. Barazzetti et al. present an innovative two-step methodology (cloud-toBIM-to-FEM); a historic BIM can be converted to a finite element model for structural simulation [60]. Ren et al. develop the refined finite element model of buildings and building community, and a finite element analysis was carried out on the high-rise building community subjected to extreme earthquakes based on BIM [61]. Patil et al. develop a process that combines 3D laser scanning, BIM, and FEA, to evaluate the structural integrity of a curtain wall [62].

Combining BIM and the numerical analysis of geotechnical engineering intends to enable to safeguard the construction safety of major infrastructure projects which is the long-term direction to the civil engineering disciplines. Current analytical methodologies, such as the numerical simulation model without integrating design information and on-site monitoring information, are difficult to meet the needs of dynamic analysis of underground engineering, especially for analyzing the potential safety hazards of the deep foundation excavation process. Furthermore, combining BIM with numerical simulation of engineering for safety analysis was more commonly used in the ground projects [63]. However, none of them is applicable for the timely analysis and control in the deep foundation construction safety. Furthermore, few of them could have performed the analysis on the ground settlement and horizontal displacement during the excavation of the deep foundation pit by using the BIM, the FEA, and the finite difference method (FDM), but the above research studies have provided us with a means towards further research efforts.

\section{An Approach for the Construction Safety of the Deep Foundation Based on BIM}

This paper proposed an approach (combining BIM, FEA, and FDM) for the deep foundation pit construction safety to dynamically predict the construction safety risk. The approach for the deep foundation excavation safety for the deep foundation is mainly composed of three procedures: model creation and integration based on BIM, data conversion from BIM-ANSYS-FLAC3D, and safety analysis of deep foundation excavation. The method is a precontrol method for identifying the safety hazards timely and preventing accidents on construction sites, which is different from the traditional construction safety approaches.

To implement the safety analysis of the deep foundation pit excavation in water-rich soft soils, the 3D information model and the bracing structure are first established by using
Revit software, and the two models can be integrated into one system platform through the IFC standards. IFC is an international specification for product data exchange and sharing for the construction industry and is also the intermediate objects for data conversion between BIM models and structural analysis software. Although IFC is a rich and neutral schema, the most difficult obstacles on successful data conversion from BIM-ANSYS-FLAC3D using the IFC standard are data redundancy and information inaccuracy $[11,15]$. Apart from IFC, Revit redevelopment can be used to realize data conversion between REVIT and ANSYS.

FLAC (Fast Lagrangian Analysis of Continua) is an explicit finite difference code, because of many advantages in dealing with geotechnical engineering problems, and FLAC3D has a large acceptance rate in geotechnical engineering applications. However, an important limitation of FLAC3D is the difficulty in geometry creation and meshing. ANSYS is the widely used finite element software that provides a powerful tool for the meshing of solid models. Furthermore, as geotechnical engineering, some complications may arise during the calculation (nonconvergence, negative values) due to the nonlinearity of the soil using ANSYS software for numerical simulation. Therefore, the commonly used method is to build a finite element model in common practice and meshes using ANSYS software by the engineers, and then, it can be imported into the FLAC3D for calculation and analysis through the interface data conversion. As the finite element method was the same as the finite difference method in the preprocessing of the research object, this article attempts to build a BIM model using the Revit software and convert the BIM model to an ANSYS model by using the Revit API and the C\# language and then automatically generate a FLAC3D model through data conversion after meshing (Figure 1).

This paper presents an approach for the construction safety of the deep foundation pit in water-rich soft soils based on BIM (Figure 2). The implementation process of construction safety analysis is as follows. This is a three-step study with an expected goal at every step.

Step 1: creating a BIM model of deep foundation engineering using Autodesk Revit. The objective is to integrate models into the system platform that can support the visualization and data exchange and sharing.

Step 2: transformation between a Revit-based BIM model and a finite element model (FEM). The goal is to obtain comprehensive information from the BIM model to create the finite element model so that it could be further used for the analysis in Step 3.

Step 3: meshes the FEA model and performs FLAC3D to accurately identify the potential safety hazards to safeguard the construction safety of deep excavations. The objective of this study is to analyze the force bearing of soil and bracing structure stiffness during the deep foundation excavation using FLAC3D and to seek for the higher-risk nodes that may induce greater 


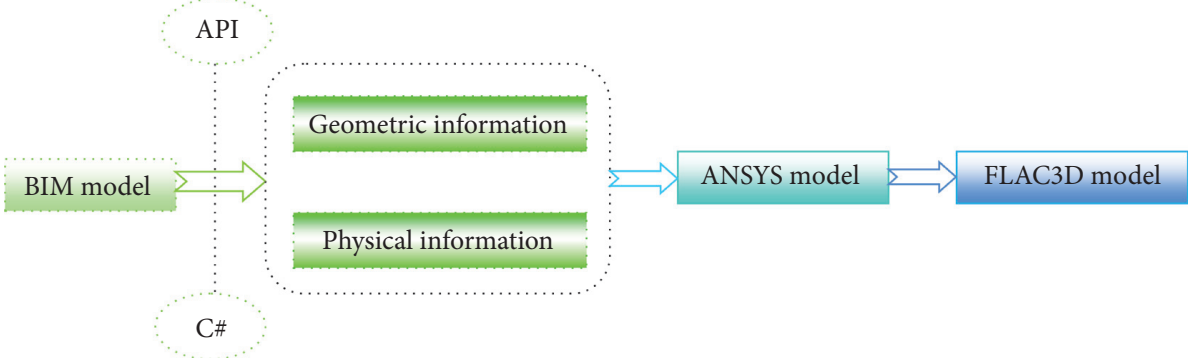

FIGURE 1: Basic process of model transformation.

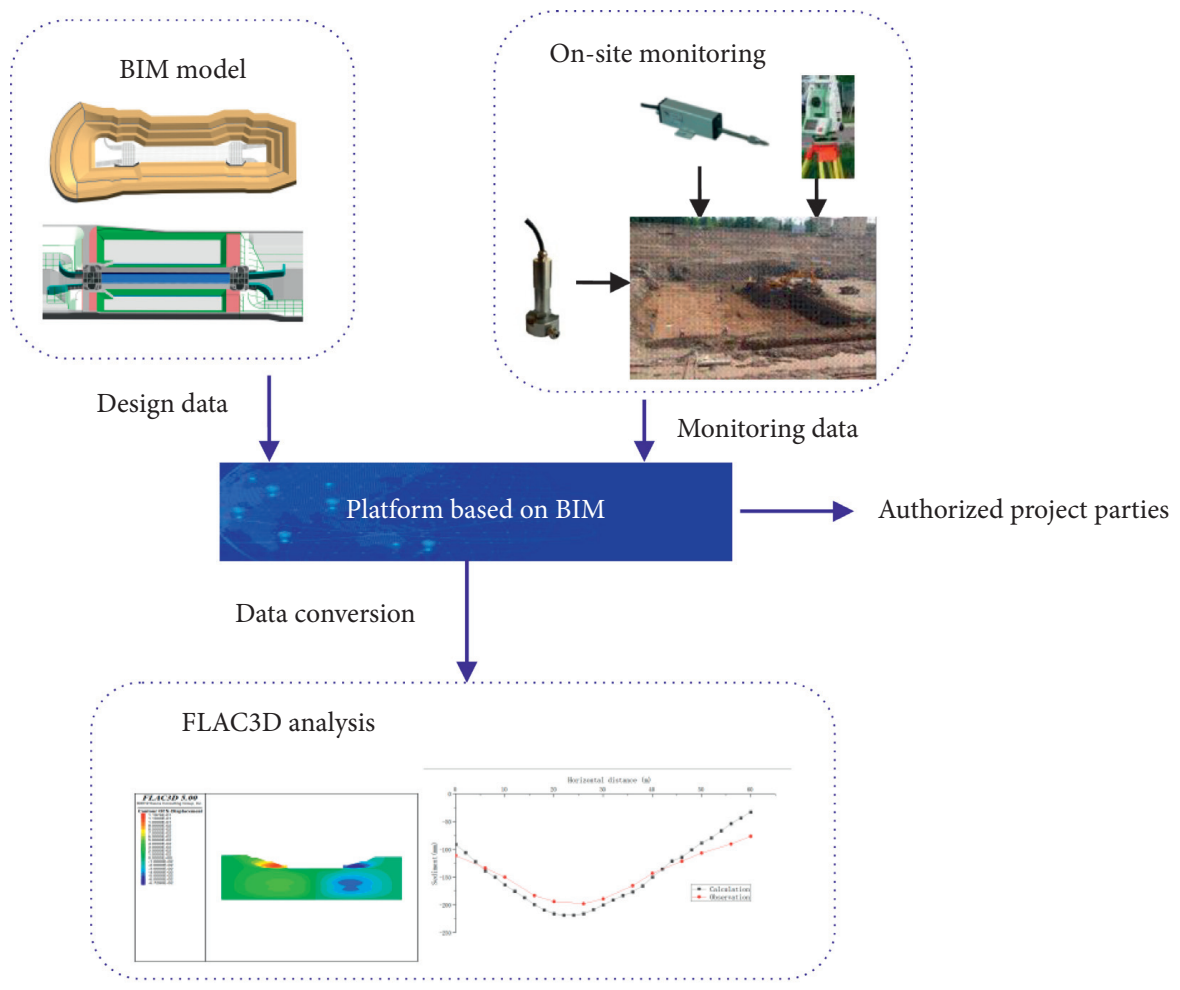

Figure 2: The implementation process of construction safety analysis of deep foundation excavation.

settlement and displacement. Understanding the potential risk beforehand can help stakeholders to take remedial actions on time.

3.1. Model Creation and Integration. Collecting all kinds of information about the geometry data of construction components, the design parametric, the engineering geological situation, and adjacent buildings which are related to the project helps to establish a 3D information model for a deep foundation based on BIM. The load information required for structural analysis should be extracted from the 3D information model to form the structural information model. IFC standards are used to integrate the 3D information model and the structural information model, so as to form the information model of structural safety of deep excavations. BIM technology is used to build the bracing structure model including the steel support and cast bored piles. A 3D information model and a bracing structure model are integrated into the BIM-based system platform with the data interfacing. Therefore, the $4 \mathrm{D}$ building information model for deep excavations is established by connecting the information of construction progress. The $4 \mathrm{D}$ model that integrates various types of information will be used to simulate the deep foundation excavation processes to resolve any potential design conflicts and provided the foundation for finite element analysis. Selecting the layout program of reasonable monitoring point and identifying key locations required monitoring (high-risk areas) are the basis of the monitoring work and can also be used for preevaluating the ground settlement and horizontal displacement.

3.2. Data Conversion from BIM-ANSYS-FLAC3D. Revit software provides the application programming interface (API) allowing the developer to write programs in C\# (or $\mathrm{C}++)$ that are compatible with .NET. C\# language is used in this article in that the development environment is the Microsoft Visual Studio and Microsoft NET Framework 4.5. 


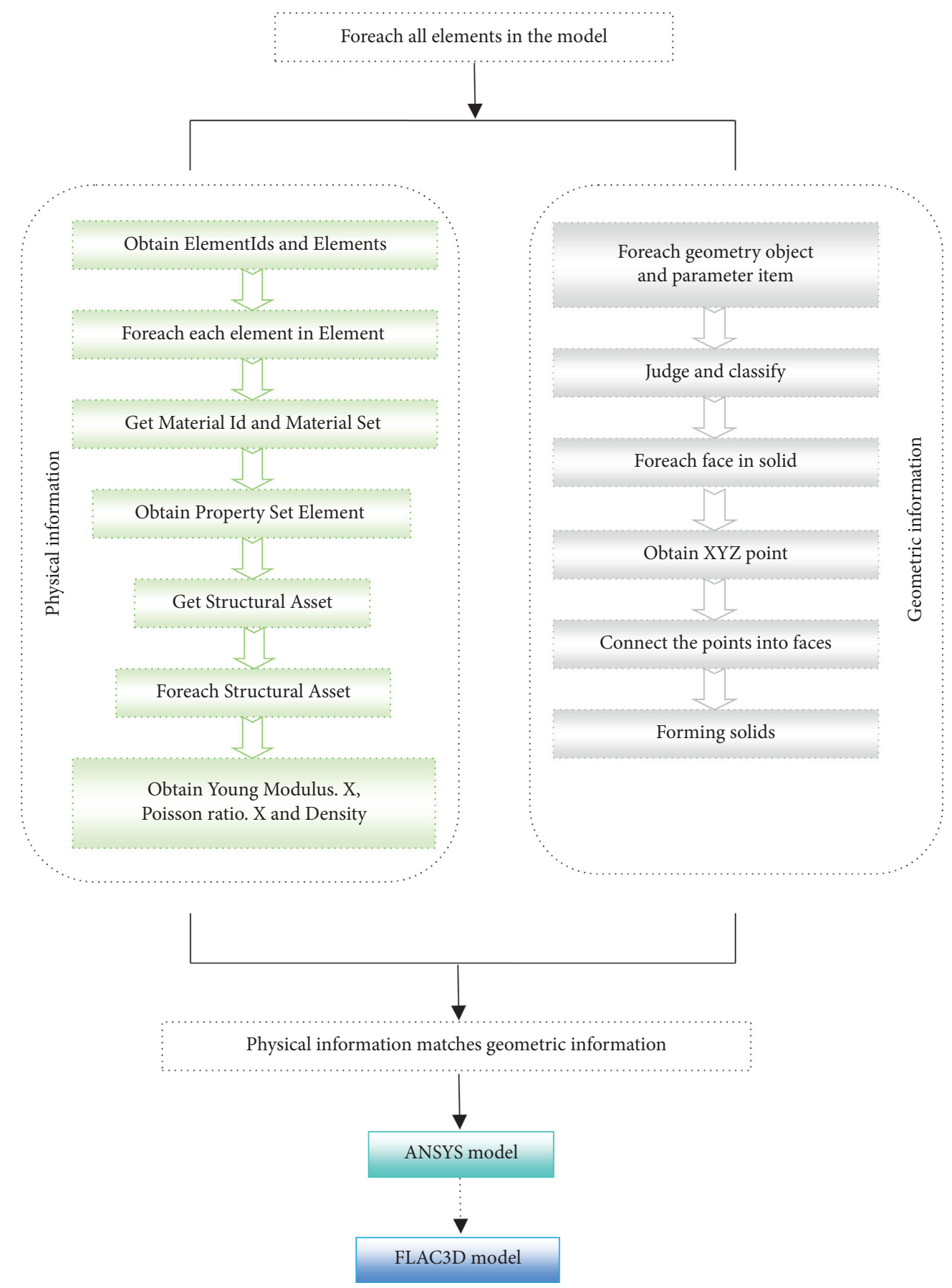

FIGURE 3: The logic of data extraction within the conversion algorithm between BIM and ANSYS model.

The secondary developed process of Revit is demonstrated in Figure 3.

3.2.1. Extraction of Physical Information. The first step is to search and filter all elements in the Revit model to determine the Family Symbol of the Element and classification and to number the different Family Instances according to the Family Symbol and store all structural members of the same type in a collection. Foreach each element in Element Collectors and obtain Material Id and Material Set. Foreach Material, obtain Property Set Element and Structural Asset, and physical information required for structural analysis, such as the elastic modulus, the Poisson coefficient, and Density, can be extracted from the properties of Structural Asset. According to different physical parameters of structural members in the Revit model, each set of different physical information corresponds to a Structural Asset number.

3.2.2. Extraction of Geometry Information. Foreach all elements in the Revit model, geometry information, and property type of each element can be obtained, including some parameters customized by the designer (for example, 
the cohesion of soil). Foreach all faces in the family instance and all key points in the faces, and obtain XYZ point (key points), XYZ point is then connected to form a face, and then the face is combined into a solid.

\subsubsection{Matching of Geometric Information and Physical} Information. After the above steps, the physical information and geometric information of the Revit model should be extracted and converted into structural 3D entities that are meant to be used for structural analysis. Each structural member of the automatically generated ANSYS model has a unique number, and there exists a one-to-one correspondence between the structural members in the Revit model and the structural entities members in ANSYS. According to the Structural Asset number in order, the structural members with the same asset properties can be found, and then add the physical information such as the elastic modulus, the Poisson coefficient, and Density; the physical parameters are output in the format of ANSYS parametric design language (APDL).

Conversion of the ANSYS model to the FLAC3D model for the analysis through the interface program has been used extensively. Due to space limitations, the details of data conversion are not introduced here.

\subsection{Safety Analysis of Deep Foundation Excavation.} Because the design model is related to the information for construction progress, and the monitoring data are related to the building elements through the monitoring points, data for the design model, structural model, and bracing structure model will be updated simultaneously as construction progresses advancing. The $4 \mathrm{D}$ model that integrates various types of information will be used to simulate the deep foundation excavation progresses to resolve any potential design conflicts and provided the foundation for finite element analysis.

Soil excavation is simulated according to the actual construction schedule, simulating the influence of different reinforcement measures on the ground surface settlement, and horizontal displacement can also be implemented. Selecting the layout program of reasonable monitoring point and identifying key locations required monitoring (high-risk areas) are the basis of the monitoring work and can also be used for preevaluating the ground surface settlement and horizontal displacement.

In the actual construction process, the working state of the entire structure would be dynamically tracked such as the force bearing of soil and deformation of bracing structure through the use of the vertical borehole inclinometers and total station. And then integration of information will be collected into the BIM-based system platform. The finite element model is then generated from the BIM model by the data interface (see Step 2) and it will be meshed using ANSYS software. At last, it will be imported into the FLAC3D for calculation and analysis. The analysis required for any given key points can be performed, such as the analysis on stress-strain distributions, displacement, and critical buckling loads in the soil or bracing structure at a given point, or the comparative analysis on the data of historical statistics of the same monitoring point in the region, that include the real-time monitoring stress value,

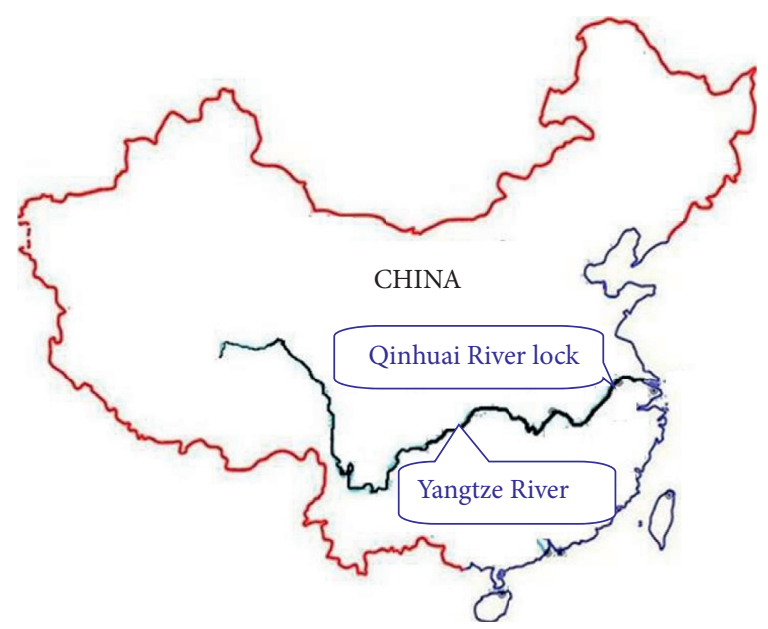

FIgURE 4: Location of Qinhuai River ship lock.

the theoretically calculated stress value, and the early warning stress value. Determining whether the monitoring stress value exceeds the early warning stress value contributes to make timely decisions and avoid accidents.

\section{Case Study: Qinhuai River Lock}

4.1. Project Review. Qinhuai River ship lock is located in Nanjing, Jiangsu Province, China, $1.5 \mathrm{~km}$ west from the Yangtze River, and it is the only ship lock that connects the Yangtze River to the Inland waterway transport in Nanjing (Figure 4). More than 200 ships carrying goods per day have to wait to pass, which far exceeds the designed capacity. Thus, the Qinhuai River ship lock was decided to be rebuilt to upgrade its traffic capacity. The newly built Qinhuai River ship lock is designed according to the level IV ship lock, and the maximum ship tonnage is 1,000 tons. The project consists of hydraulic structures (including upper stream and lower gate and lock chambers), the gate valve of the metal structure, electrical engineering, and other buildings. The lower gate is located on the flood control line of the Qinhuai River hub, and a highway bridge is crossing above, and thus, the construction section of the lower gate should be regarded as the area with the highest risk level.

4.1.1. Geological and Hydrological Conditions. Figure 5 shows the engineering geological condition of the ship lock, and the type of landform in the project site belongs to the Yangtze River floodplain, which is mainly composed of silty clay and fine sand. As shown, the top layer is a $0.8 \sim$ $4.1 \mathrm{~m}$ thick silty clay with the characteristics of high compressibility and high pore, which is a potential control layer affecting the stability of deep excavation. The second layer is composed of silty clay and silt, in which silty clay dominates the layer. Beneath is the silty sand layer with liquefaction potential. The Qinhuai New River is connected to the Yangtze River, which involves comprehensive hydraulic conditions. The construction site is characterized by highly permeable water-bearing soft soil layers, and groundwater in the site includes spore diving and microconfined water; 


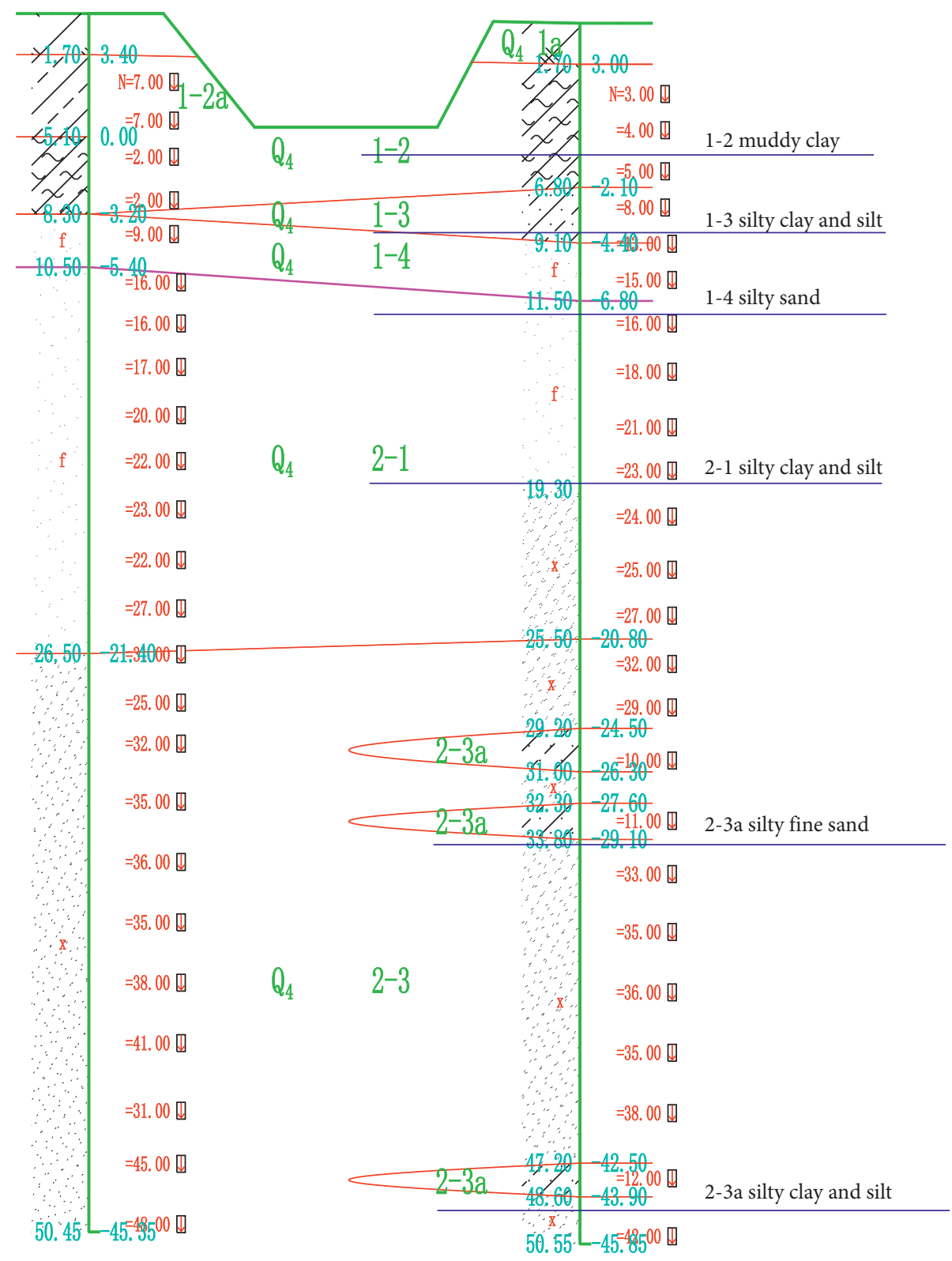

Figure 5: Soil layers (provided by Yangtze River Nanjing Waterway Bureau).

besides these, the groundwater is closely linked with river water.

4.1.2. Project Characteristics. The following characteristics make this project different from others:

(1) The stratum crossing the excavation is mainly muddy-clays, silty-clays, and silty-sands, with very weak formation and poor self-stability of the soil layer and it is easy to be deformed or crept.

(2) The ship lock is located in the section of the Qinhuai New River, near to the entrance of the Yangtze River. Due to the high water level difference between the inside and outside of the deep excavation, it is necessary to drain water during the deep excavation, which may cause intense seepage. Because the deep foundation excavated in the soft-plastic clay area, it will take a long time to reach the stable water level after the excavation was completed. There is the pressurized water below the deep foundation bottom of pouring concrete. When the pressure of the pressurized water increases more than the weight of the soil of deep foundation bottom, it is necessary to carry out decompression and precipitation of the pressurized water for preventing the water inrush. Foundation pit excavation will induce surface settlements of a few centimeters because of 


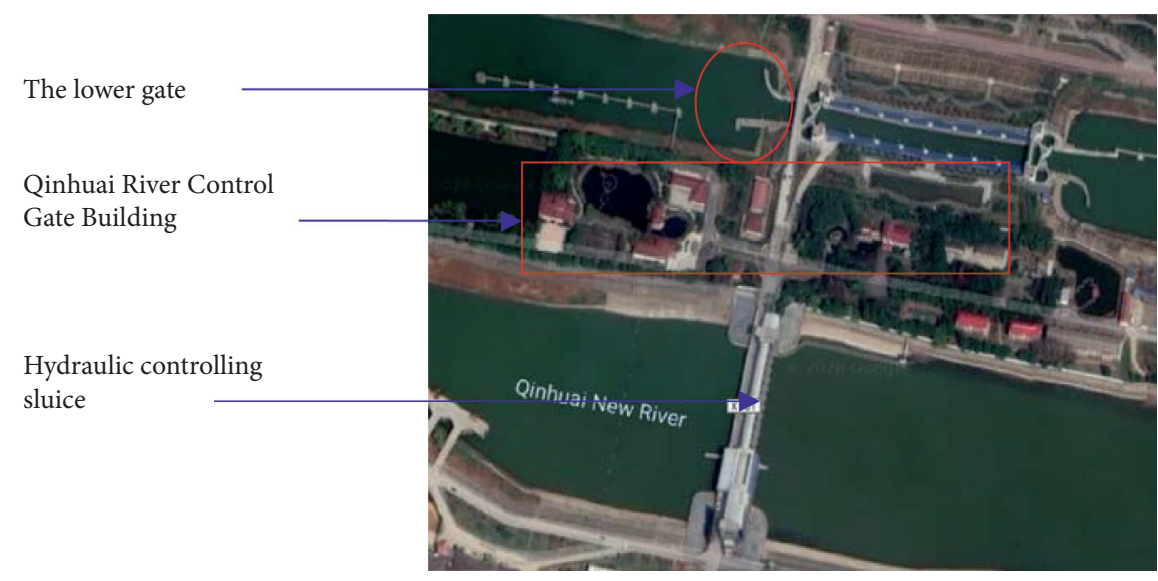

FIGURE 6: Distribution map of surrounding buildings at the lower gate (provided by Yangtze River Nanjing Waterway Bureau).

groundwater drainage and precipitation, and settlements of this order of magnitude are sufficient to pose a potential threat to the foundation and bracing structure and causing sliding/collapse.

(3) The lower gate is located on the flood control line of the Qinhuai River, where a highway bridge is crossing above. The excavation depth of the lower gate is up to $20 \mathrm{~m}$, and the bracing structure is $100 \mathrm{~m}$ away from the running hydraulic controlling sluice on the left side (Figure 6). The protection of the hydraulic controlling sluice was thus taken as key sections for the successful completion of the project, which poses a great challenge for deep excavation and precipitation and the support of the bracing structure. Excavation of deep foundation (excavation depth of $20 \mathrm{~m}$ ) may induce the inhomogeneous settlement of the adjacent building (Qinhuai River Control Gate Building), as much as tilting or collapse. Therefore, the unfavorable engineering geological condition in the ship lock construction site, especially in the excavation of the deep foundation for the lower gate, potentially makes the slope unstable to endanger the safety of the highway bridge and hydraulic controlling sluice. In reports from the technical support unit and related engineering supervisors, the construction safety of the lower gate also is regarded as one of the key problems in this project. Thus, in this paper, the construction of the lower gate is taken as an example, to explore the construction safety methods of deep excavations in water-rich soft soils based on BIM.

Besides, there is relatively little experience accumulating for the deformation control of deep foundation in soft soils to the important water conservancy facilities projects. Although the conservative design is conducive to safe construction, it was not encouraged since it would cost more money.

4.1.3. Excavation Plan and Reinforcement Scheme. To solve the above problem, the owners, the design firms, the construction firms, and the technical support unit have communicated on the bracing structure plans and plans for cantilever steel sheet pile and cast-in-situ bored piles, and high-pressure rotary spray reinforcement was finally determined. The method of excavation used for the deep foundation was segmentation, zoning, and stratification, and the construction procedures are as follows:

Construction step 1: to reduce the water pressure and enhance the strength of soil at the bottom of the deep foundation, the double-row steel sheet piles as cofferdam are built near the entrance of the Yangtze River before the deep foundation excavation; the upstream and downstream of the Qinhuai River are filled with earth to form gravity-type water retaining cofferdam, and then, the water is pumped out from inside the cofferdam.

Construction step 2: taken into account the effect of the seepage, $5 \mathrm{~m}$ wide inner subcofferdam is filled in the enclosed area of the steel sheet pile cofferdam. Around the inner subcofferdam, the high-pressure jet grouting is used to set up a vertical antiseepage curtain wall.

Construction step 3: the excavation of the deep excavation is divided into three levels (irregular foundation pit due to environmental constraints). A vertical antiseepage curtain wall is set on the inner side of the slope after completing the excavation of the first level slope. To reduce the bottom heave and the bracing structure deformation, the deep cement mixing piles are used to reinforce the muddy clay soft soil for enhanced stability. Precipitation measures for deep wells around the foundation are used during the excavation to prevent the penetration deformation.

At the same time, different measures of reinforcement were adopted, depending on the geological situation and degrees of stability. In particular, in the lower gate, the measures are given as follows: reinforce the slope and set up one row of cantilever steel sheet pile on the left side of the deep foundation of the lower gate (adjacent to the hydraulic controlling sluice and Qinhuai River Control Gate Building).

Construction step 4: concrete cushion layer is poured timely after completing the foundation excavation. 
Construction step 5: the bottom plate, the middle floor, the chamber wall, the gate of the lower gate, etc., are, respectively, constructed by adopting a bottom-up construction approach.

4.2. Model Creation and Simulation of the Qinhuai River Ship Lock. The 3D information model and the bracing structure of the Qinhuai River ship lock are established by using Revit, which are then integrated into the system platform through the IFC interface. The collision detection between the bracing components and the structural and architectural components is implemented using Navisworks software to eliminate conflicting design. The projects are decomposed using a work breakdown structure (WBS) approach, and the information on construction progress is connected. The association between building components and progress information is realized. And then, the $4 \mathrm{D}$ information model of the Qinhuai River ship lock is established, as shown in Figure 7.

As shown in Figure 8, the construction process simulation of the Qinhuai River ship lock is implemented. The double-row steel sheet piles as cofferdam are built near the entrance of the Yangtze River before the excavation of the deep foundation, to form a gravity retaining cofferdam. Around the inner subcofferdam, the high-pressure jet grouting is used to set up a vertical antiseepage curtain wall. The excavation of the deep excavation is divided into three levels, and a vertical antiseepage curtain wall is set on the inner side of the slope after completing the excavation of the first level slope. After the construction of the deep excavation is completed, concrete cushion layer, the bottom plate, the middle floor, the chamber wall, upper and lower gates, lock chambers are, respectively, constructed by adopting a bottom-up construction approach.

A finite element model was established by extracting data from the $4 \mathrm{D}$ model of the platform. Then further analysis was completed to potentially predict any future structural issues and ground settlement by combining the BIM, FEM, and FLAC3D such as simulating the ground surface settlement or deformation that may be caused by the construction of the lower gate (Qinhuai River ship lock) before excavation; simulating the construction process of the Qinhuai River ship lock to identify the potential risk; simulating the ground surface settlement or deformation that may be caused by the construction of the lower gate, especially for the highway bridge and the hydraulic controlling sluice; and the stress and displacement of the bracing structure, to identify high-risk areas and set up the monitoring points for the Qinhuai River ship lock and associate monitoring points with $4 \mathrm{D}$ model.

4.3. Optimizing the Monitoring Scheme. Employing investigation of geological conditions in the site, finite element computation, and comparative analysis of the monitoring scheme provided by the design firms, the layout of monitoring points was found to be insufficient to cover the entire settlement affected zone, so that the monitoring scheme was adjusted, and the monitoring plan is proposed to serve the construction safety of deep excavation reliably and economically. Figure 9 shows the plane layout of the ship lock slope and the engineering geological condition.

4.3.1. Slope Monitoring of the Deep Foundation. For observation of deformation at the top and slope surface of the slope of the deep foundation, at two-stage platform surface of the slope, and at the slope top, 57 deformation monitoring points were installed at $20 \mathrm{~m}$ spacing, in which 31 were assigned to two-stage platform surface and 26 to the slope top. At the slope top of the deep foundation, 12 deep horizontal displacement monitoring points were installed at $40 \mathrm{~m}$ spacing to observe the deep horizontal displacement for the soil.

\subsubsection{Water Level Monitoring Outside Deep Foundation.} To monitor the change in the groundwater level, 17 porous tube type piezometers were installed at $30 \mathrm{~m}$ spacing at the slope top around the deep foundation. Two monitoring sections for observation on the variation of water levels are set between the ship lock and the hydraulic controlling sluice, with every monitoring point installed at intervals of $30 \mathrm{~m}$. Thus, the total number is 8 .

4.3.3. The Monitoring of Cofferdam. To avoid a catastrophic collapse of slope due to the water outside the foundation pit seeping into the retaining structure and infiltrating into the foundation pit, 10 water level pipes were installed at $30 \mathrm{~m}$ spacing outside the vertical antiseepage curtain wall, to monitor the variation of groundwater level during excavation.

To monitor with high precision of the displacement of the cofferdam, 4 displacement monitoring points were installed at the upstream cofferdam along the axial direction. Two deformation monitoring points and two deep horizontal displacement monitoring points were installed at the shoulder slope of the inner subcofferdam of the upstream cofferdam. Three surface deformation observation points were installed at the downstream cofferdam along the axial direction. Three deep horizontal displacement monitoring points were installed at the top center of cofferdam along the axial direction.

4.3.4. Safety Monitoring of the Adjacent Buildings. A total of 24 settlement monitoring points were installed on each side of the pier of the hydraulic controlling sluice, i.e., 12 per side. A settlement monitoring point was installed at each of the four corners of the management station of the hydraulic controlling sluice, and two inclining observation points were installed at the surface of the outer wall facing the foundation pit.

\section{Results and Discussion}

Excavation of the deep foundation of the lower gate will induce the inhomogeneous settlement of the running hydraulic controlling sluice, as much as tilting and collapse, so that the construction safety of the lower gate is regarded as 


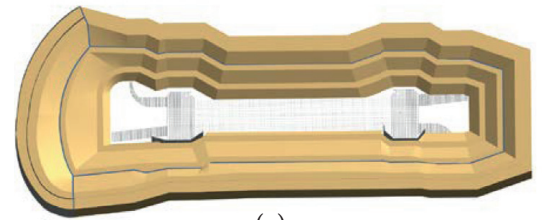

(a)

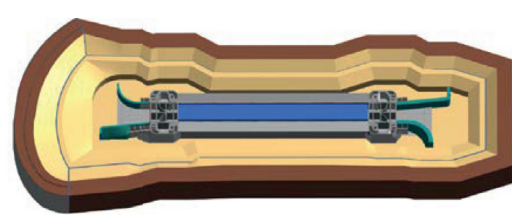

(b)

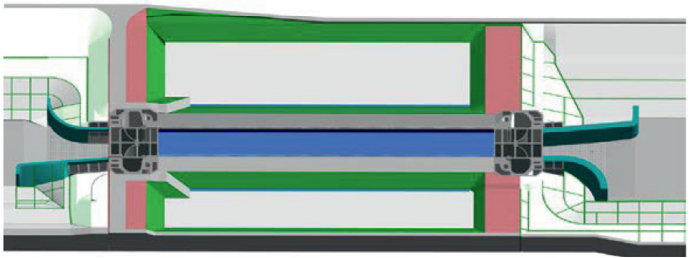

FIgURE 7: Qinhuai River ship lock model. (a) Cast-in-situ bored piles were set at the bottom of the hydraulic structures (including upper and lower gates, lock chambers, etc.), and then the excavation of the deep excavation in three levels was completed. (b) The bottom plate, the middle floor, the chamber wall, the gate of the lower gate, etc., are, respectively, constructed by adopting a bottom-up construction approach.

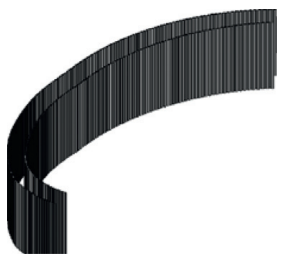

(a)

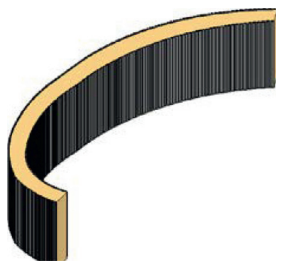

(b)

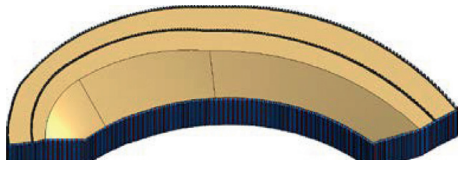

(c)

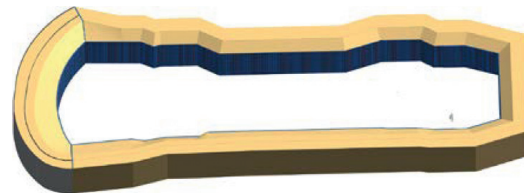

(d)

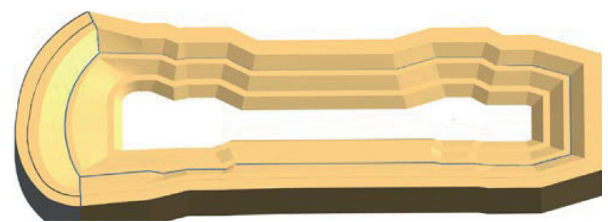

(e)

Figure 8: Simulation of the deep foundation construction processes. (a) The double-row steel sheet piles as cofferdam are built near the entrance of the Yangtze River before the deep foundation excavation. (b) The upstream and downstream of the Qinhuai River are filled with earth to form gravity-type water retaining cofferdam. (c) Inner subcofferdam is filled in the enclosed area of the steel sheet pile cofferdam. A vertical antiseepage curtain wall was set up around the inner subcofferdam. (d) A vertical antiseepage curtain wall is set on the inner side of the slope. (e) Completed foundation excavation.

the key goal in the construction of this project. Thus, next, the construction of the lower gate is taken as an example, to explore the construction safety methods of deep excavations in water-rich soft soils based on BIM.

\subsection{Establishment and Analysis of FLAC 3D Model}

5.1.1. FLAC3D Model Based on a Unified Data Source. By implementing the data conversion process of BIMANSYS-FLAC3D as described in Section 3.2, data that can be used for the safety analysis are extracted to generate ANSYS models and then automatically generate the FLAC3D model through the data exchange interfaces after meshing. The Mohr-Coulomb model in FLAC3D was adopted in this study for numerical simulations.

According to the actual geological conditions and the models calculating the requirements, the three-dimensional calculation model of the foundation pit at the lower gate was set as $230 \mathrm{~m} \times 80 \mathrm{~m} \times 60 \mathrm{~m}$, with a total of 58320 units and 65923 nodes. The boundary conditions are as follows: the surface of the model is a free boundary, the bottom is a fixed boundary condition, and the four sides are normal displacement constraints. The input parameters of the clay layers are shown in Table 1 . The fundamentals of the elasticplastic Mohr-Coulomb model can be found in the FLAC 3D user's manual. The main factors which must be considered in the calculation are as follows: 


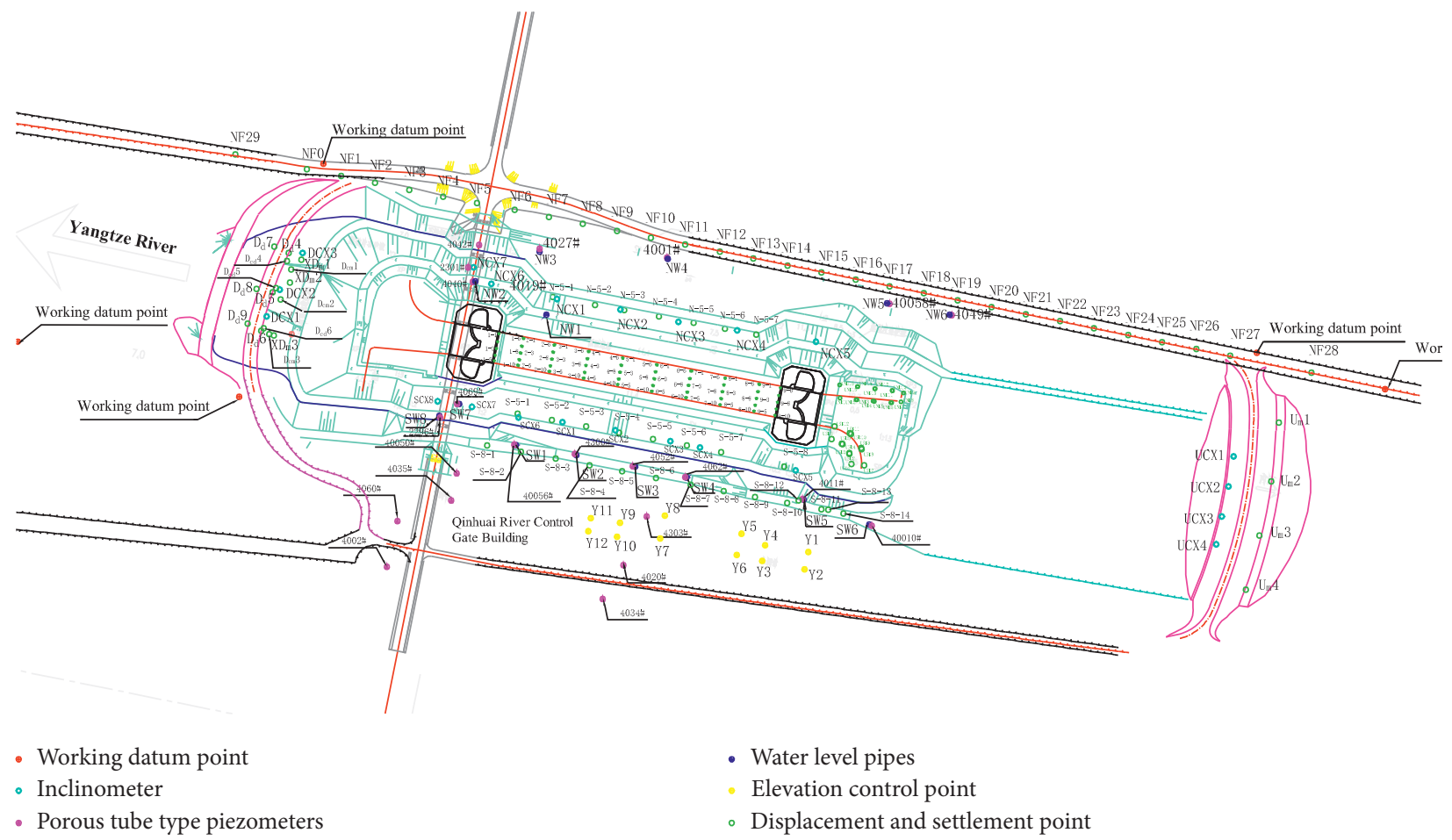

FIGURE 9: Distribution of monitoring points (provided by Yangtze River Nanjing Waterway Bureau).

TABLE 1: Geotechnical properties of soil layers.

\begin{tabular}{lccccc}
\hline Soil layer & $\rho\left(\mathrm{kg} / \mathrm{m}^{3}\right)$ & $E(\mathrm{MPa})$ & $v$ & $c(\mathrm{kPa})$ & $\phi\left(^{\circ}\right)$ \\
\hline 1b (soil-filling) & 1860 & 41 & 0.35 & 19.5 & 5.8 \\
1-2 (muddy clay) & 1760 & 34 & 0.35 & 12 & 4.3 \\
1-4 (silty sand) & 1910 & 38 & 0.35 & 5 & 28 \\
2-1 (silty clay and silt) & 1890 & 17 & 0.3 & 17.2 & 32.7 \\
2-3 (fine sand) & 1950 & 38 & 0.3 & & 33.4 \\
2-3a (silty clay and silt) & 1890 & 17 & 0.3 & 17.2 & 6.9 \\
\hline
\end{tabular}

(1) The model has been established for the lower gate of the high-risk zones according to the actual situation of the project, where the project assignment approximately meets the strain problem conditions.

(2) Vertical excavation from elevation $0 \mathrm{~m}$ to $-4 \mathrm{~m}$ is designed in the slope toe of deep excavation due to the limitation of slope length, which requires the use of steel sheet piles as the deep foundation pit protection to improve construction safety.

(3) The actual sequence adopted at the site was followed closely in simulation.

5.1.2. Numerical Analysis. Owing to the high requirement for settlement control of deep foundation excavation in water-rich soft soils, especially the excavation of the lower gate, it is significant for the lower gate to take protection measures before construction. Vertical excavation from elevation $0 \mathrm{~m}$ to $-4 \mathrm{~m}$ is designed in the slope toe of deep excavation due to the limitation of slope length of the lower gate, which requires the use of steel sheet piles as the deep foundation protection to improve construction site safety. Taking into account the increased costs due to increased support and the deformation and damage due to no additional support, two construction schemes were put forward excavation of the lower gate, as well as numerical simulation for the development of soil stress and strain under two working schemes was carried out by using FLAC3D.

Construction scheme 1: the steel sheet pile was built after excavation to elevation $0 \mathrm{~m}$. Setting up steel sheet piles before vertical excavation is a common practice in support design.

Construction scheme 2: the steel sheet pile was built after vertical excavation to elevation $-2 \mathrm{~m}$. Firstly, vertically excavates to elevation $0 \mathrm{~m}$ without support, there after the soil shear stress will increase within a reasonable range and the soil strength will also experience more release during excavation. Then the steel sheet pile was built after vertical excavation to elevation $-2 \mathrm{~m}$. The area where there is soil stress improvement is not a region of potential slip arc that affects the overall stability so that it has little impact on the overall shear strength and stability of the soil.

(1) Shear Stress Analysis. Figures 10 and 11 show the shear stress distribution of Construction scheme 1 and Construction scheme 2, respectively. The potential slip surfaces present large shear stress, indicating that the large shear deformation at that location is caused by the excavation process. There is shear stress concentration in the soil at the bottom of the deep foundation in front of the steel sheet pile, 


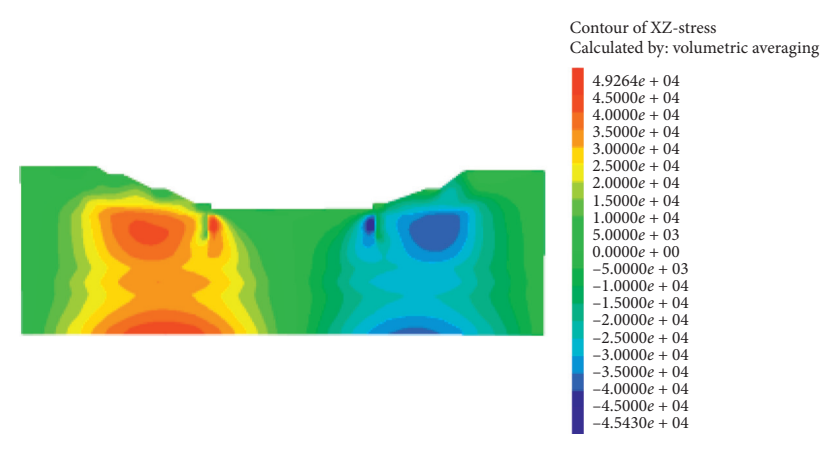

(a)

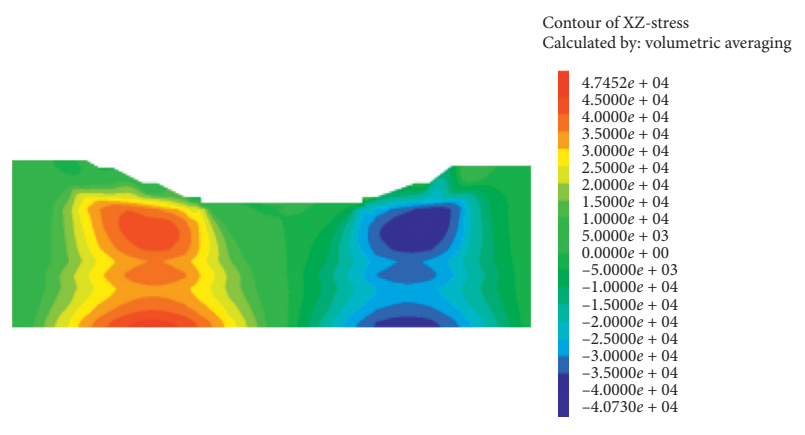

(b)

FIGURe 10: Distribution of shear stress after foundation excavation to elevation $-2 \mathrm{~m}$. (a) Construction scheme 1. (b) Construction scheme 1.

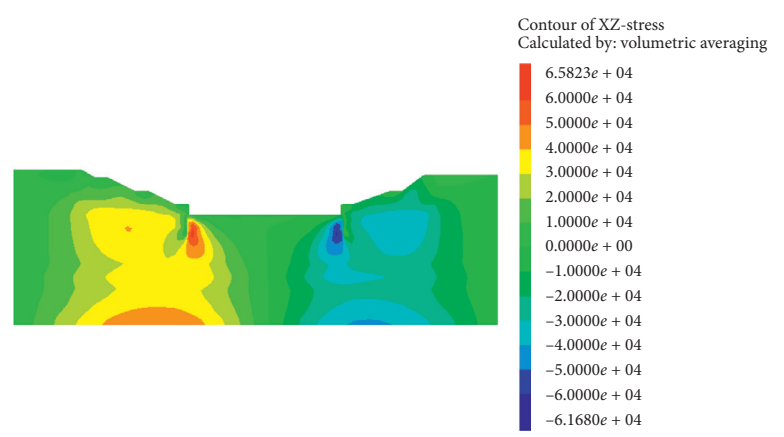

(a)

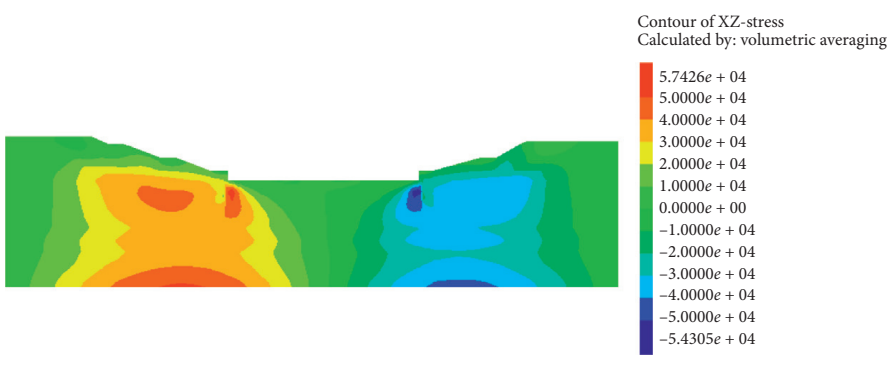

(b)

FIGURE 11: Distribution of shear stress after foundation excavation to elevation $-4 \mathrm{~m}$. (a) Construction scheme 1. (b) Construction scheme 2.

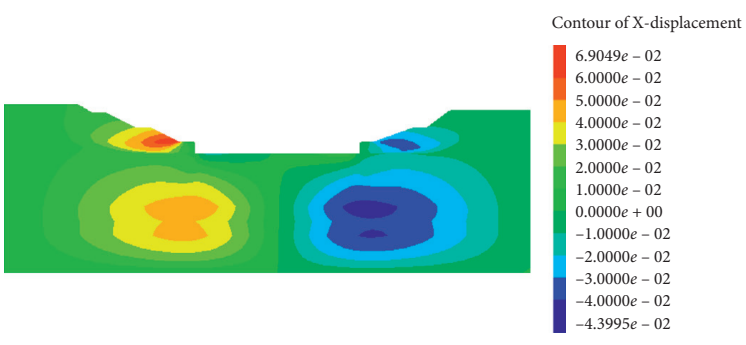

(a)

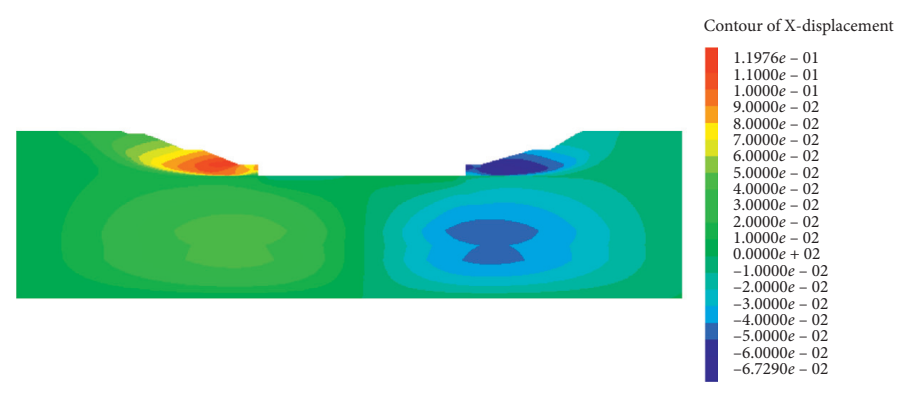

(b)

Figure 12: Distribution of horizontal displacement after foundation excavation to elevation $-4 \mathrm{~m}$. Construction scheme 2 was selected based on the results of the above finite element analysis. (a) Construction scheme 1. (b) Construction scheme 2.

which indicates that the soil strength in the passive zone is fully exerted. Shear stress in the passive zone for the Construction scheme 2 is lower than that in the Construction scheme 1, which is caused by a reduction in the loading of steel sheet pile due to delay in setting up of the steel sheet piles.

(2) Displacement Analysis. Figure 12 shows the large horizontal displacement and relative displacement in the potential landslide zones when excavation to elevation $-4 \mathrm{~m}$; however, the horizontal displacement and relative displacement distribution in the Construction scheme 2 exhibit more extensive than that in the Construction scheme 1. This is because the steel sheet pile in the Construction scheme 1 was installed earlier, and the horizontal displacement is suppressed, increasing loading. In Construction scheme 2, the soil surface shear strength can be fully released and a large shear displacement and corresponding horizontal displacement is produced due to delay in setting up of the steel sheet piles.

(3) Settlement Analysis. As shown in Figure 13, the maximum settlement of the numerical simulated reached $-220 \mathrm{~mm}$, which was close to the limiting value proposed by the owner unit. All participants reached an agreement that 


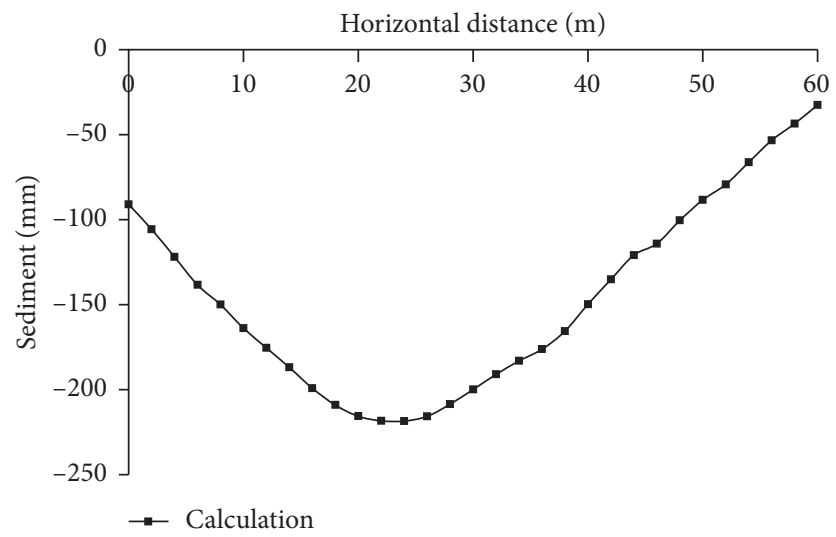

FIgURE 13: Settlement curve after foundation excavation to elevation $-4 \mathrm{~m}$.

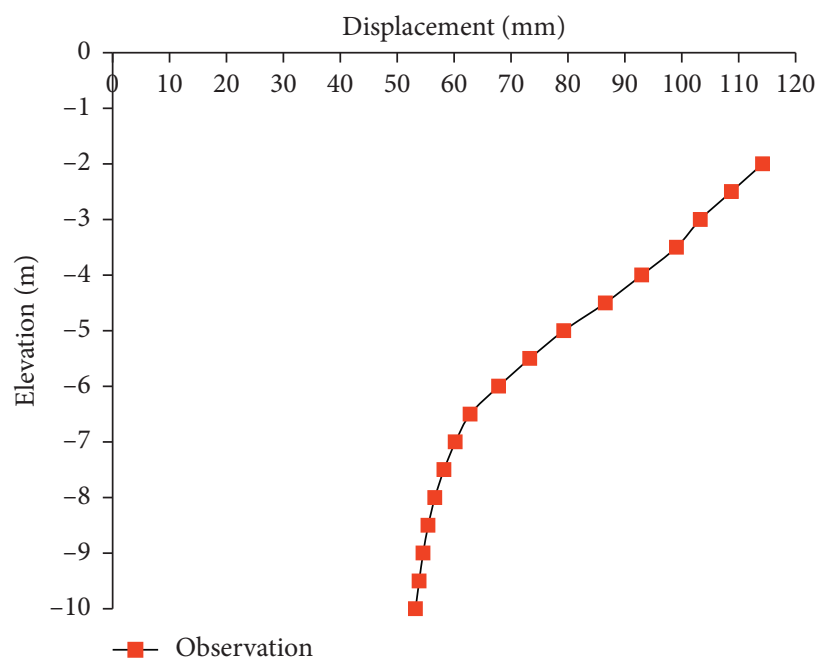

(a)

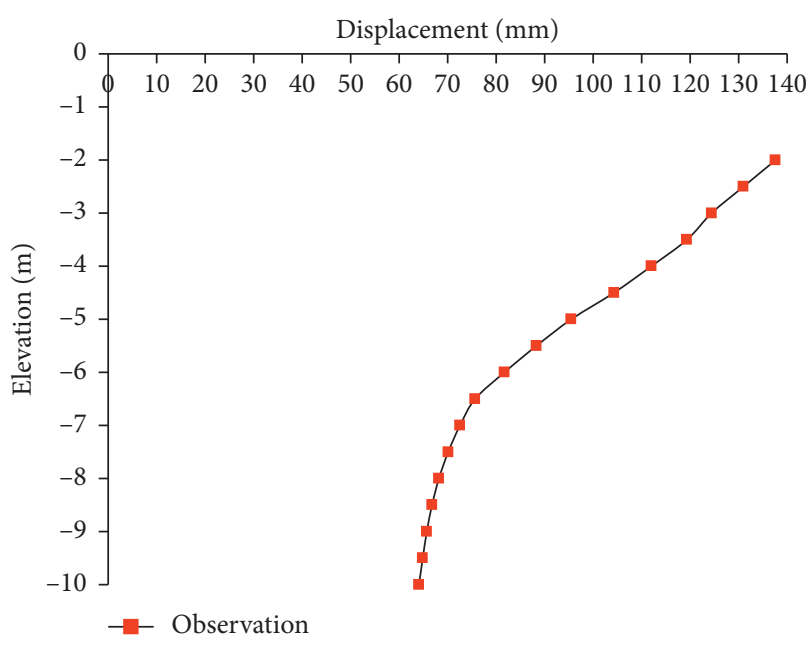

(b)

Figure 14: Measured displacements. (a) Excavation to elevation $-2 \mathrm{~m}$. (b) Excavation to elevation $-4 \mathrm{~m}$.

some more effective measures must be taken to reduce the ground surface settlement. The technical support unit proposes that increasing a row of steel sheet piles on the left side of the lower gate's foundation was conducted as a control measure. The distance between the two rows of steel sheet piles is 3 meters, and the proposal was accepted by the owner unit and the construction unit.

\subsection{Results and Discussion}

5.2.1. Results. Data collection and transmission is performed by the hydrostatic leveling systems (high precision vibrating wire sensor, connecting line, data collection module, etc.). Several hydrostatic leveling systems have been installed in different locations at construction sites, and each hydrostatic leveling is connected to the data collection module. The monitoring data are transmitted to the BIMbased system platform through the wireless launch module from the data acquisition instrument, these data are classified and processed by the technical staff, and then the project participants can view. By implementing the data conversion process of BIM-ANSYS-FLAC3D, Figure 14 shows the automatic monitoring results after the lower gate's foundation was excavated to elevation $-2 \mathrm{~m}$ and $-4 \mathrm{~m}$. The maximum displacement occurs at the inner side of the surface of vertical excavation, and the maximum displacement value is about $115 \mathrm{~mm}$ when excavation to elevation $-2 \mathrm{~m}$ and is about $14 \mathrm{~m}$ when excavation to elevation $-4 \mathrm{~m}$. The displacement of the soil decreased with increasing distance from the foundation.

5.2.2. Discussion. Following the results of Section 5.2.1, it is found that the comparison between the two curves is shown in Figure 15 (excavation to elevation $-4 \mathrm{~m}$ ), and the calculated displacement of the soil shows a good agreement with the measurement data. Note that the monitored data measured at excavation to elevation $-4 \mathrm{~m}$ were used for comparison. The distance from the foundation is $-8 \mathrm{~m}$ and beneath, the measured and calculated soil displacement values are the same, about $65 \mathrm{~mm}$. The 


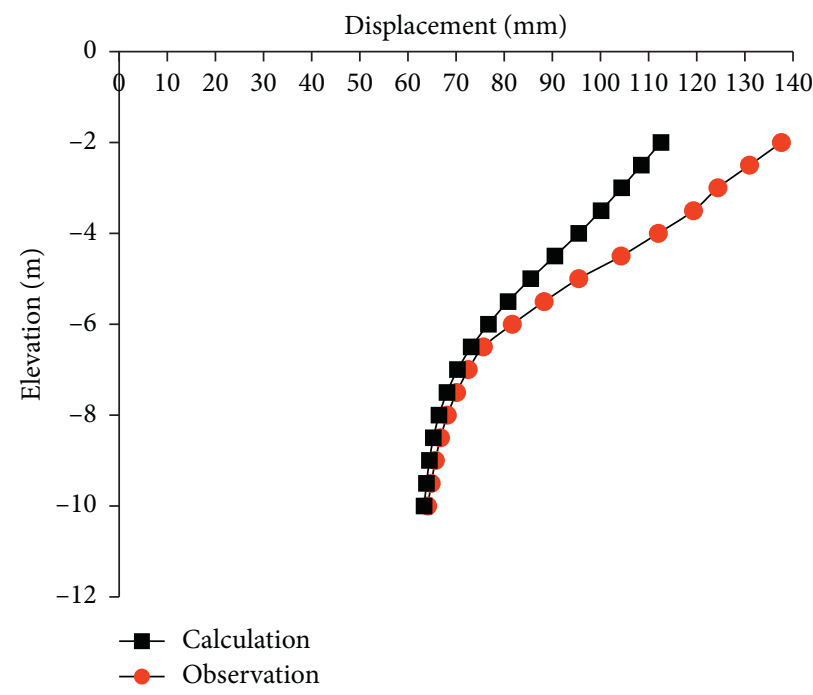

FIgURE 15: Comparison of measured displacements with computations (excavation to elevation $-4 \mathrm{~m}$ ).

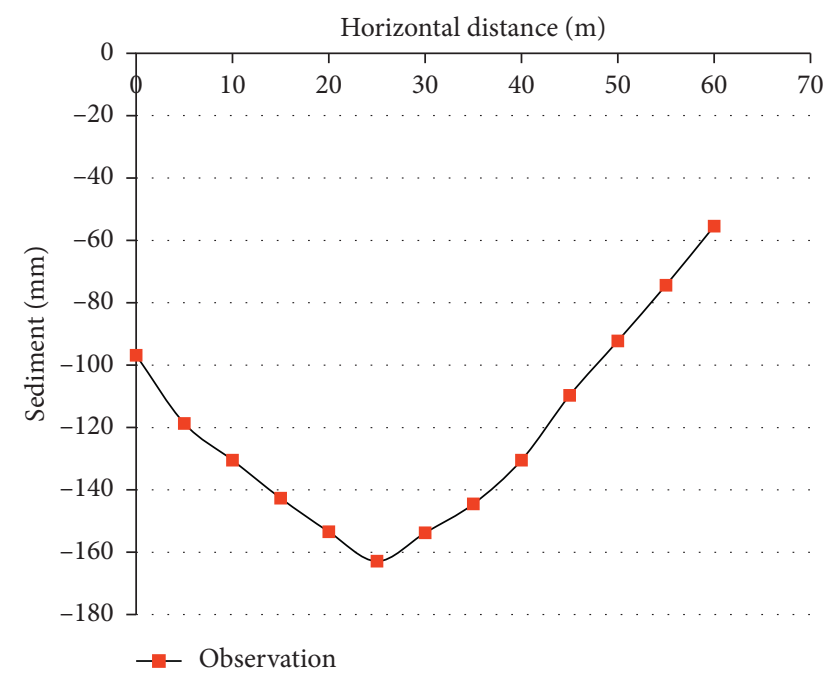

(a)

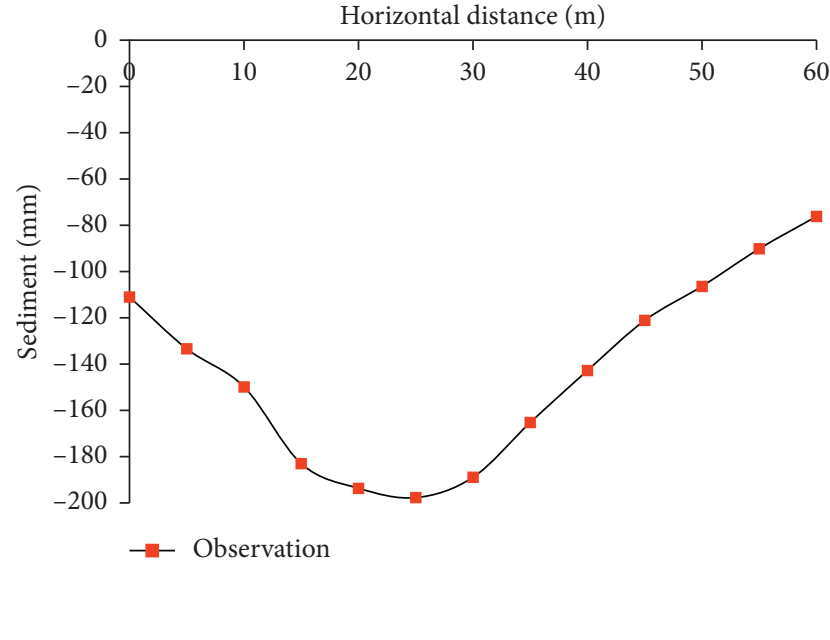

(b)

Figure 16: Measured settlement. (a) Excavation to elevation $-2 \mathrm{~m}$. (b) Excavation to elevation $-4 \mathrm{~m}$.

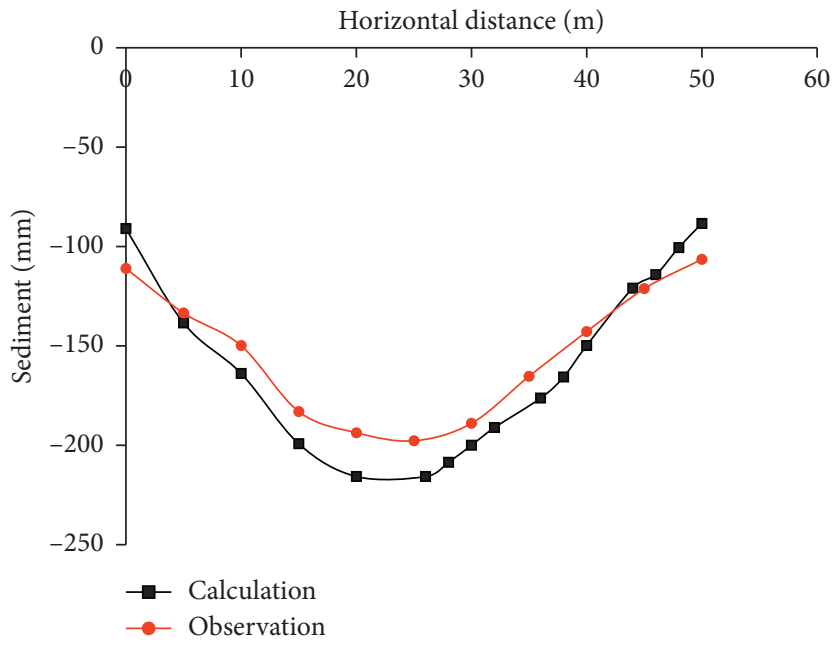

FIgURE 17: Comparison of measured settlement with computations (excavation to elevation $-4 \mathrm{~m}$ ). 


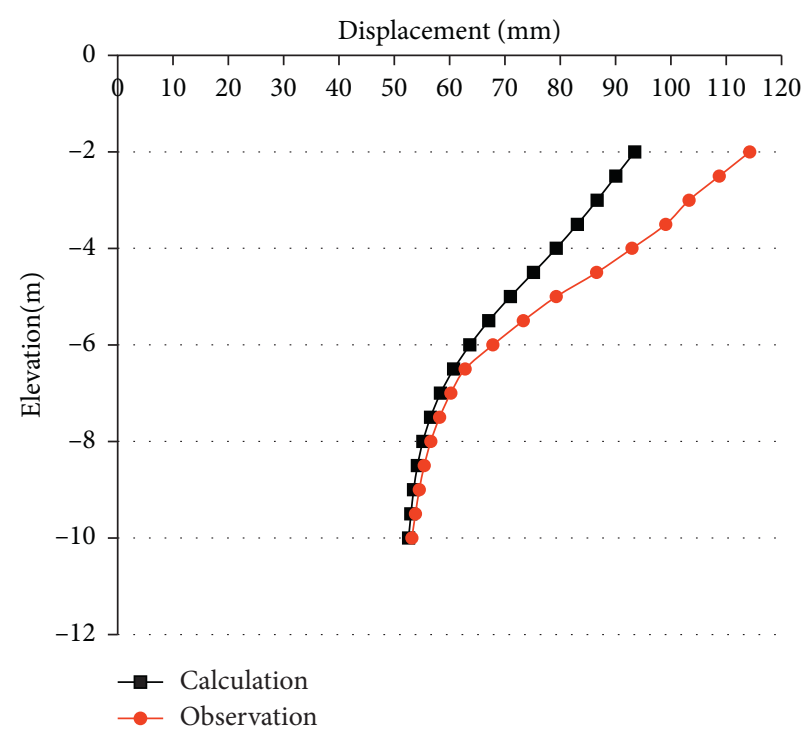

(a)

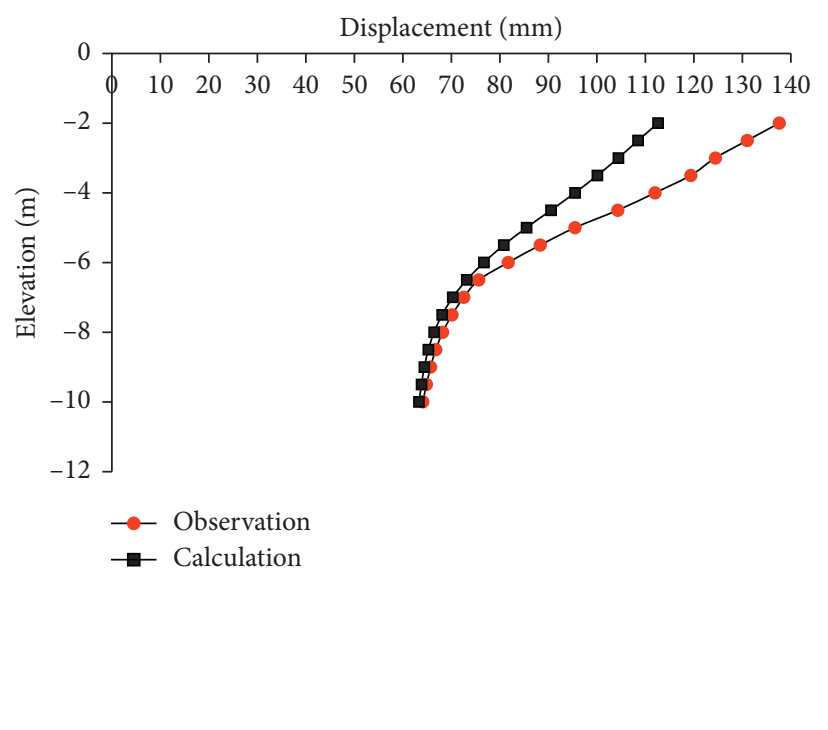

(b)

FIgURE 18: Comparison of measured displacement with computations. (a) Excavation to elevation $-2 \mathrm{~m}$. (b) Excavation to elevation $-4 \mathrm{~m}$.

distance from the foundation is $-2 \mathrm{~m}$, the calculated soil displacement value is $112 \mathrm{~mm}$, but the measured value reaches $137 \mathrm{~mm}$.

Figure 16 shows the automatic monitoring results after the excavation of the lower gate's foundation to elevation $-2 \mathrm{~m}$ and $-4 \mathrm{~m}$. The curve shows that the maximum settlement occurs at a distance of $25 \mathrm{~m}$ from the steel sheet pile. The maximum settlement value is about $-160 \mathrm{~mm}$ when excavation to elevation $-2 \mathrm{~m}$, while it is about $-200 \mathrm{~mm}$ when excavation to elevation $-4 \mathrm{~m}$, and this shows that it is the most dangerous during the period before pouring the concrete bottom layer, after the foundation excavation is completed (excavation to elevation $-4 \mathrm{~m}$ ).

Figure 17 compares the calculated and the measured settlement data. The predicted ground settlement matches fairly well with the measured settlement data, the maximum settlement of the numerical simulated reached $-218 \mathrm{~mm}$ when excavation to elevation $-4 \mathrm{~m}$, and the measured maximum settlement is $-198 \mathrm{~mm}$, which means the feedback control is effective during the foundation excavation.

The measured displacements are close to the value of the calculated displacement when excavated to elevation $-2 \mathrm{~m}$, and the first steel sheet pile was installed for the reinforcement at time.

When the excavation is close to elevation $-4 \mathrm{~m}$, the monitoring team found that the displacement was increasing from $130 \mathrm{~mm}$ (elevation $-2 \mathrm{~m}$ ) to $138 \mathrm{~mm}$, and multiple cracks with a width of $0.2 \mathrm{~cm}-0.5 \mathrm{~cm}$ were found on the ground of the Qinhuai River Control Gate Building. A simulation analysis was carried out using field measured data, which shows that the displacement will continue to increase and may be close to $150 \mathrm{~mm}$ or more, which is a serious threat to buildings such as the running hydraulic controlling sluice, Qinhuai River Control Gate Building, and the highway bridge. After the on-site investigation, it was found that the second steel sheet pile was not installed following the construction plan to reduce expenses. The owner, technical team, and construction unit communicate online immediately via the system platform, and the proposal was proposed by the technical team as follows: observing the settlement while constructing, pouring concrete cushions timely after the foundation excavation is completed, and steel support should be quickly installed (steel support was inclined to brace on steel sheet pile) after the pouring concrete cushions are completed to effectively control the displacement. The displacement is finally controlled under $-140 \mathrm{~mm}$ after reinforcement (Figure 18).

\section{Conclusions and Future Work}

This paper presents an approach for the construction safety of the deep foundation pit in water-rich soft soils. The ground surface settlement and horizontal displacement during the deep foundation excavation are analyzed by using FLAC3D, and the purpose of which is to predict the safety risk that might emerge in the future so that reasonable control measures can be taken. Then, a case study of the Qinhuai River Ship Lock Project is presented to illustrate the feasibility of this approach. The following conclusions can be drawn:

(1) The 3D information model and the bracing structure are established by using Revit software, and the two models are integrated into a system platform through the IFC standards. The monitoring data during the construction process can also be integrated into this platform. Therefore, a unified data source is founded for the safe construction of the deep foundation pit in water-rich soft soils. Based on the datasets of this platform, the construction process of the deep foundation excavation can be simulated, which, furthermore, provides guidance for a reasonable layout of the monitoring points and 
also lays the foundation to evaluate the ground surface settlement and horizontal displacement.

(2) The geometric and physical information of the BIM model is extracted to generate the ANSYS model and then automatically converted to the FLAC3D model for structural analysis through the data exchange interfaces after meshing. The BIM-ANSYS-FLAC3D data conversion performs satisfactorily in terms of conversion quality, accuracy, and timeliness, which greatly helps the engineers to capture more accurate information during the generation from the REVIT model to the FLAC3D model. Meanwhile, the ground surface settlement and horizontal displacement were efficiently analyzed by using FLAC3D, which helps the project stakeholders to continuously monitor the changes during the deep foundation excavation and to predict the potential safety hazards that might emerge so that reasonable control measures can be taken.

(3) A case study is performed to validate the proposed approach for the construction safety of the deep foundation pit in water-rich soft soils, namely, the Project of Qinhuai River Ship Lock. Since the excavation and the after-construction stages of this project have been completed smoothly, the approach presented in this article has been proved applicable and feasible.

Although the method has been proposed for the deep foundation construction conditions, it has the potential for wider use in underground engineering, since many of the issues faced are similar in another underground engineering. However, it is clear that further study is needed in the following aspects: on the one hand, the integration of BIMANSYS-FLAC3D is not fully seamless when it comes to complete automation, and future work is needed to accommodate the smooth transition between different formats and recognition of a variety of shapes and geometry. On the other hand, as foundation excavation was constructed during the dry season, the analysis of the effect of the foundation excavation and groundwater interaction on the settlement/displacement during the foundation excavation has not been implemented. Therefore in the future, we must make more efforts to acquire more detailed hydrogeological data for more accurate settlement predictions.

\section{Data Availability}

All data included in this study are available upon request by contact with the corresponding author.

\section{Conflicts of Interest}

The authors declare that they have no conflicts of interest.

\section{Acknowledgments}

The authors gratefully acknowledge all the participants interviewed for this study and offer many thanks for the contributions to data collection by the staff of the College of
Civil and Transportation Engineering of Hohai University. This research was supported by the Natural Science Foundation of Anhui Provincial Department of Education of China (no. KJ2018A0619) and the Training Programme Foundation for the Talents by the Anhui Provincial Department of Education (no. gxbjZD59).

\section{References}

[1] K. Terzaghi, R. B. Peck, and G. Mesri, Soil Mechanics in Engineering Practice, John Wiley \& Sons, Hoboken, NY, USA, 1996.

[2] R. Schäfer and T. Triantafyllidis., "Modelling of earth and water pressure development during diaphragm wall construction in soft clay," International Journal for Numerical and Analytical Methods in Geomechanics, vol. 28, no. 13, pp. 1305-1326, 2004.

[3] X. N. Gong and Y. C. Gao, The Design Manual for Excavating Deep Foundation Pit Engineering, Construction Industry Press, Beijing, China, 1998, in Chinese.

[4] R. Hussain et al., "Safety regulation classification system to support BIM based safety management. ISARC," in Proceedings of the International Symposium on Automation and Robotics in Construction, vol. 34, June 2017.

[5] J. Wang, S. Zhang, and J. Teizer, "Geotechnical and safety protective equipment planning using range point cloud data and rule checking in building information modeling," $A u$ tomation in Construction, vol. 49, pp. 250-261, 2015.

[6] N. Khan, A. K. Ali, M. J. Skibniewski, D. Y. Lee, and C. Park, "Excavation safety modeling approach using BIM and VPL," Advances in Civil Engineering, vol. 2019, Article ID 1515808, 15 pages, 2019.

[7] A. F. Waly and W. Y. Thabet, "A virtual construction environment for preconstruction planning," Automation in Construction, vol. 12, no. 2, pp. 139-154, 2003.

[8] S. Zhang, J. Teizer, J.-K. Lee, C. M. Eastman, and M. Venugopal, "Building information modeling (BIM) and safety: automatic safety checking of construction models and schedules," $A u$ tomation in Construction, vol. 29, pp. 183-195, 2013.

[9] M. J. Skibniewski, "Information technology applications in construction safety assurance," Journal of Civil Engineering and Management, vol. 20, no. 6, pp. 778-794, 2014.

[10] W. W. S. Lu and H. Li, "Building information modeling and changing construction practices," Automation in Construction, vol. 20, no. 2, pp. 99-100, 2011.

[11] M. Venugopal, C. M. Eastman, R. Sacks, and J. Teizer, "Semantics of model views for information exchanges using the industry foundation class schema," Advanced Engineering Informatics, vol. 26, no. 2, pp. 411-428, 2012.

[12] H. Xu, J. Feng, and S. Li, "Users-orientated evaluation of building information model in the Chinese construction industry," Automation in Construction, vol. 39, pp. 32-46, 2014.

[13] A. I. Mana, Finite element analyses of deep excavation behavior in soft clay, Ph.D. Thesis, Stanford University, Stanford, CA, USA, 1976.

[14] R. Jardim-Goncalves and A. Grilo, "Building information modeling and interoperability," Automation in Construction, vol. 19, no. 4, p. 387, 2010.

[15] Z.-Z. Hu, X.-Y. Zhang, H.-W. Wang, and M. Kassem, "Improving interoperability between architectural and structural design models: an industry foundation classes-based approach with web-based tools," Automation in Construction, vol. 66, pp. 29-42, 2016. 
[16] C. Koch, A. Vonthron, and M. König, "A tunnel information modelling framework to support management, simulations and visualisations in mechanised tunnelling projects," $A u$ tomation in Construction, vol. 83, pp. 78-90, 2017.

[17] S. Sakurai, S. Akutagawa, K. Takeuchi, M. Shinji, and N. Shimizu, "Back analysis for tunnel engineering as a modern observational method," Tunnelling and Underground Space Technology, vol. 18, no. 2-3, pp. 185-196, 2003.

[18] K. Terzaghi and R. B. Peck, Soil Mechanics in Engineering Practice, Wiley, NewYork, NY, USA, 1948.

[19] R. B. Peck, "Deep excavations and tunneling in soft ground," in Proceedings of the 7th International Conference on Soil Mechanics and Foundation Engineering, pp. 225-290, Mexico City, Mexico, 1969.

[20] R. B. Peck, "Advantages and limitations of the observational method in applied soil mechanics," Géotechnique, vol. 19, no. 2, pp. 171-187, 1969.

[21] P. L. Bransby and G. W. E. Milligan, "Soil deformations near cantilever sheet pile walls," Géotechnique, vol. 25, no. 2, pp. 175-195, 1975.

[22] C. K. Shen, "Centrifuge modeling of lateral earth support," Journal of the Geotechnical Engineering Division, vol. 108, no. 9, pp. 1150-1164, 1982.

[23] M. D. Bolton and W. Powrie, "Behaviour of diaphragm walls in clay prior to collapse," Géotechnique, vol. 38, no. 2, pp. 167-189, 1988.

[24] A. J. Powderham, "An overview of the observational method: development in cut and cover and bored tunnelling projects," Géotechnique, vol. 44, no. 4, pp. 619-636, 1994.

[25] W. Schubert, "The development of the observational method," Geomechanik und Tunnelbau, vol. 1, no. 5, pp. 352-357, 2008.

[26] Y. M. A. Hashash, C. Marulanda, J. Ghaboussi, and S. Jung, "Novel approach to integration of numerical modeling and field observations for deep excavations," Journal of Geotechnical and Geoenvironmental Engineering, vol. 132, no. 8, pp. 1019-1031, 2006.

[27] Y. Ikuta, M. Maruoka, M. Aoki, and E. Sato, "Application of the observational method to a deep basement excavated using the top-down method," Géotechnique, vol. 44, no. 4, pp. 655-679, 1994.

[28] R. J. Finno and M. Calvello, "Supported excavations: observational method and inverse modeling," Journal of Geotechnical and Geoenvironmental Engineering, vol. 131, no. 7, pp. 826-836, 2005.

[29] M. Calvello, "From the observational method to "observational modelling" of geotechnical engineering boundary value problems," in Proceedings of the Geotechnical Safety and Reliability, pp. 101-117, Denver, CO, USA, 2017.

[30] Y. Chen, "Application of new observational method on deep excavation retaining wall design in london clay," Dissertation, University of Cambridge, Cambridge, UK, 2020.

[31] W. Zhang, A. T. C. Goh, and F. Xuan, "A simple prediction model for wall deflection caused by braced excavation in clays," Computers and Geotechnics, vol. 63, pp. 67-72, 2015.

[32] L. Wang, Z. Luo, J. Xiao, and C. H. Juang, "Probabilistic inverse analysis of excavation-induced wall and ground responses for assessing damage potential of adjacent buildings," Geotechnical and Geological Engineering, vol. 32, no. 2, pp. 273-285, 2014.

[33] W. Zhang, Y. Zhang, and A. T. C. Goh, "Multivariate adaptive regression splines for inverse analysis of soil and wall properties in braced excavation," Tunnelling and Underground Space Technology, vol. 64, pp. 24-33, 2017.

[34] G. T. Kung, C. H. Juang, E. C. Hsiao, and Y. M. Hashash, "Simplified model for wall deflection and ground-surface settlement caused by braced excavation in clays," Journal of Geotechnical and Geoenvironmental Engineering, vol. 133, no. 6, pp. 731-747, 2007.

[35] Y. Hong, C. W. W. Ng, G. B. Liu, and T. Liu, "Three-dimensional deformation behaviour of a multi-propped excavation at a "greenfield" site at Shanghai soft clay," Tunnelling and Underground Space Technology, vol. 45, pp. 249-259, 2015.

[36] R. Fuentes, A. Pillai, and P. Ferreira, "Lessons learnt from a deep excavation for future application of the observational method," Journal of Rock Mechanics and Geotechnical Engineering, vol. 10, no. 3, pp. 468-485, 2018.

[37] M. N. Houhou, F. Emeriault, and A. Belounar, "Three-dimensional numerical back-analysis of a monitored deep excavation retained by strutted diaphragm walls," Tunnelling and Underground Space Technology, vol. 83, pp. 153-164, 2019.

[38] N. Benmebarek, S. Benmebarek, R. Kastner, and A.-H. Soubra, "Passive and active earth pressures in the presence of groundwater flow," Géotechnique, vol. 56, no. 3, pp. 149-158, 2006.

[39] A. Lim and C.-Y. Ou, "Stress paths in deep excavations under undrained conditions and its influence on deformation analysis," Tunnelling and Underground Space Technology, vol. 63, pp. 118-132, 2017.

[40] K. Arai et al., "Interpretation of concrete top base foundation behaviour on soft ground by coupled stress flow finite element analysis," Numerical Methods in Geomechanics, vol. 1, pp. 625-630, Routledge, Abingdon, UK, 2017.

[41] Y. Nielsen and O. Koseoglu, "Wireless networking in tunnelling projects," Tunnelling and Underground Space Technology, vol. 22, no. 3, pp. 252-261, 2007.

[42] X. Y. Xie and L. Feng, "Real-time health monitoring system for power tunnel," in Proceedings of the GeoCongress: State of the Art and Practice in Geotechnical Engineering, pp. 30993108, Oakland, CA, USA, March 2012.

[43] J. Liu, "Prediction and treatment of stratum movement around deep foundation pits of underground walls," Underground Engineering and Tunnel, vol. 2, pp. 2-15, 1993.

[44] I. H. Wong, T. Y. Poh, and H. L. Chuah, "Performance of excavations for depressed expressway in Singapore," Journal of Geotechnical and Geoenvironmental Engineering, vol. 123, no. 7, pp. 617-625, 1997.

[45] P.-G. Chuah and C.-Y. Ou, "Shape of ground surface settlement profiles caused by excavation," Canadian Geotechnical Journal, vol. 35, no. 6, pp. 1004-1017, 1998.

[46] E. H. Y. Leung and C. W. W. Ng, "Wall and ground movements associated with deep excavations supported by cast in situ wall in mixed ground conditions," Journal of Geotechnical and Geoenvironmental Engineering, vol. 133, no. 2, pp. 129-143, 2007.

[47] M. Caudron, Experimental and numerical study of the soilstructure interaction in the occurrence of a Sinkhole, Ph.D. Thesis, INSA of Lyon, Villeurbanne, France, 2007, in French.

[48] Y. Ding, Excavation-induced deformation and control in soft deposits, Ph.D. Thesis, Shanghai Jiao Tong University, Shanghai, China, 2009, in Chinese.

[49] L. Y. Ding and C. Zhou, "Development of web-based system for safety risk early warning in urban metro construction," Automation in Construction, vol. 34, pp. 45-55, 2013.

[50] S. Schindler, F. Hegemann, A. Alsahly et al., "An interaction platform for mechanized tunnelling. Application on the Wehrhahn-Line in Düsseldorf (Germany)/Eine Interaktionsplattform für maschinelle Tunnelvortriebe. 
Anwendung am Beispiel der Wehrhahn-Linie in Düsseldorf," Geomechanics and Tunnelling, vol. 7, no. 1, pp. 72-86, 2014.

[51] X. Xie, Q. Wang, I. Shahrour, J. Li, and B. Zhou, "A real-time interaction platform for settlement control during shield tunnelling construction," Automation in Construction, vol. 94, pp. 154-167, 2018.

[52] H. Aladag, G. Demirdögen, and Z. Isık, "Building information modeling (BIM) use in Turkish construction industry," Procedia Engineering, vol. 161, pp. 174-179, 2016.

[53] Z. Q. Liu, F. Zhang, and J. Zhang, "The building information modeling and its use for data transformation in the structural design stage," Journal of Applied Science and Engineering, vol. 19, no. 3, pp. 273-284, 2016, in Chinese.

[54] Y. R. Kim and Y. S. Cho, "The study on application of Korean BIM process in the structural design phase based on a case study," Journal of the Architectural Institute of Korea, vol. 25, pp. 19-26, 2009.

[55] A. A. Bhusar and A. R. Akhare, "Application of BIM in structural engineering," International Journal of Civil Engineering, vol. 1, no. 5, pp. 12-20, 2014.

[56] P.-H. Chen, L. Cui, C. Wan, Q. Yang, S. K. Ting, and R. L. K. Tiong, "Implementation of IFC-based web server for collaborative building design between architects and structural engineers," Automation in Construction, vol. 14, no. 1, pp. 115-128, 2005.

[57] X. Deng, T. Y. P. Chang, and X. Liu, "Automatic generation of structural model from IFCbased architectural model," Tumu Gongcheng Xuebao, vol. 40, pp. 6-12, 2007.

[58] L. Qin, X.-y. Deng, and X.-1. Liu, "Industry foundation classes based integration of architectural design and structural analysis," Journal of Shanghai Jiaotong University (Science), vol. 16, no. 1, pp. 83-90, 2011.

[59] Z. W. Chen, "Meng-gang 3 generation of refined FE model of complex structures based on BIM," Journal of Civil Engineering and Management, vol. 35, p. 5, 2018, in Chinese.

[60] L. Barazzetti, F. Banfi, R. Brumana, G. Gusmeroli, M. Previtali, and G. Schiantarelli, "Cloud-to-BIM-to-FEM: structural simulation with accurate historic BIM from laser scans," Simulation Modelling Practice and Theory, vol. 57, pp. 71-87, 2015.

[61] X. Ren, W. Fan, J. Li, and J. Chen, "Building Information Model-based finite element analysis of high-rise building community subjected to extreme earthquakes," Advances in Structural Engineering, vol. 22, no. 4, pp. 971-981, 2019.

[62] G. P. Patil, D. Chen, G. Mayo, J. Smithwick, and N. Barclay, "Implementing BIM and finite element analysis in a structural integrity investigation of curtain walls," Journal of Facility Management Education and Research, vol. 3, no. 1, pp. 27-37, 2019.

[63] R. Volk, J. Stengel, and F. Schultmann, "Building Information Modeling (BIM) for existing buildings-literature review and future needs," Automation in Construction, vol. 38, pp. 109127, 2014. 